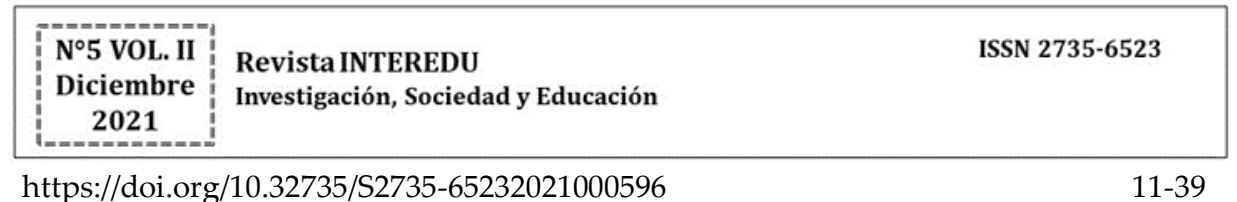

https://doi.org/10.32735/S2735-65232021000596

11-39

\title{
PROJETO DE VIDA DO PROGRAMA ENSINO INTEGRAL: PROTAGONISMO NEOLIBERAL
}

Proyecto de vida del programa de educación integral: protagonismo neoliberal

Life project of the integral education program: neoliberal protagonism

MARCELO VICENTIN
Bolsista PNPD/Capes - Universidade São Francisco (Brasil),
Universidade de Campinas (Brasil).
marcelovicentin@yahoo.com.br
http://orcid.org/0000-0003-0476-0587
CARLOS ROBERTODA SILVEIRA
Universidade São Francisco (Brasil).
carlosilveir@yahoo.com.br
https://orcid.org/0000-0002-1003-0014

\section{RESUMO}

Este artigo busca problematizar a subjetivação que emerge na formação de jovens a partir da instauração do Programa de Ensino Integral e da emergência do Projeto de Vida, que busca explorar o protagonismo juvenil como uma "disciplina" que garanta autonomia aos estudantes, permitindo que gradualmente respondam às exigências do mundo contemporâneo e suas relações com o mundo do trabalho, no desenvolvimento de habilidade que lhe permitam uma formação como pessoa autônoma, solidária e competente para continuar aprendendo ao longo da vida. Partindo da premissa "aprender a aprender" ou aprender por toda a vida, interrogamos as premissas desse Projeto de Vida, observando-o dentro do campo do neoliberalismo, como defendido por Michel Foucault (2010) e Dardot e Laval (2016), visto que atua como um modo de conduta, pois atua como uma nova razão do mundo, e, como tal, produzindo os sujeitos 
necessários para o seu funcionamento, logo, um sujeito que assume o protagonismo de sua vida, como um empreendedor de si.

Palavras-chave: Subjetivação; neoliberalismo; educação; programa ensino integral; projeto de vida.

\section{RESUMEN}

Este artículo busca problematizar la subjetividad que surge en la formación de jóvenes a partir de la instauración del Programa de Educación Integral y el surgimiento del Proyecto de Vida, que busca explorar el protagonismo juvenil como una "disciplina" que garantiza la autonomía a los estudiantes, permitiéndoles dar respuesta paulatina a las demandas del mundo contemporáneo y sus relaciones con el mundo laboral, en el desarrollo de competencias que le permitan formarse como una persona autónoma, solidaria y competente para seguir aprendiendo a lo largo de la vida. Partiendo de la premisa "aprender a aprender" o aprender para toda la vida, cuestionamos las premisas de este Proyecto de Vida, observándolo en el campo del neoliberalismo, como lo defienden Michel Foucault (2010) y Dardot y Laval (2016), ya que actúa como un modo de conducta, ya que actúa como una nueva razón del mundo y, como tal, produce los sujetos necesarios para su funcionamiento; por tanto, un sujeto que asume el protagonismo de su vida, como emprendedor de sí mismo.

Palablas claves: Subjetivación; neoliberalismo; educación; programa de educación integral; proyecto de vida.

\section{ABSTRACT}

This article seeks to problematize the subjectivity that arises in the formation of young people from the establishment of the Integral Education Program and the emergence of the Life Project, which seeks to explore youth protagonism as a "discipline" that guarantees autonomy to students, allowing 
them to gradually meet the needs of the contemporary world and their relations with the world of work, in the development of skills that allow people to train as an autonomous, supportive, and competent person, and to continue learning throughout life. Starting from the premise "learning to learn" or "learning for life", we question the premises of this Life Project, observing them in the field of neoliberalism, as defended by Michel Foucault (2010) and Dardot and Laval (2016), since it acts as a mode of behavior, as a new reason for the world, producing the necessary subjects for its functioning. In this manner, we talk about a subject who assumes the protagonism of its own life, as an entrepreneur of its own self.

Key words: Subjectivation; neoliberalism; education; integral education program; life project.

\section{INTRODUÇÃO}

A educação brasileira vem buscando caminhos que a ordenem para um modelo que se diferencie da proposta em ação desde o processo de redemocratização e a promulgação de uma nova Constituição nos anos de 1980. Com a promulgação de uma nova Lei de Diretrizes e Bases da Educação Nacional [LDB] (1996), um campo vasto para reformas educacionais ganhou corpo, tendo como apoio as mais diversas Conferências Internacionais apoiadas e dirigidas por Organizações Internacionais (UNESCO, OMC, OCDE, Banco Mundial, FMI). Esse também foi um momento de assunção de governos influenciados por pensadores neoliberais, com o avanço de discursos de reformas que se sucederam para a constituição de um novo paradigma escolar, que busca se contrapor ao modelo anterior, reestruturando a escola a partir de indicadores de eficiência, eficácia, produtividade e qualidade, tomando como exemplo modelos de gestão próprias do meio empresarial. 
Em confluência ao discurso neoliberal, ajustes fiscais buscam reduzir ou reordenar os investimentos governamentais para com a Educação, obrigando a um novo modelo de gerenciamento que observe o controle de custos e a metrificação da eficácia dos métodos pedagógicos, aproximando-a da cultura de habilidade e competências mais próximas a lógica empresarial.

De acordo com Laval (2019), a presença da lógica neoliberal apresenta três tendências que não escapam à burocracia já instituída, constituindo-se em um modelo híbrido: um, a desinstitucionalização que ocorre pela perda de autonomia e estabilidade, decorrentes dos métodos de gestão, flexibilidade, resultados e inovações; dois, a desvalorização da transmissão do cânone cultural e social, e da emancipação política, para valores econômicos de eficiência produtiva e inserção profissional; três, desintegração decorrente dos mecanismos de mercado, que valoriza a autonomia individual pelo consumo de acordo com as demandas do público.

Para o autor supracitado, essa lógica neoliberal, que exacerba a competitividade, atuando sob a formulação da OCDE, à serviço de múltiplos interesses e de uma ampla clientela, busca pela produção de sujeitos empresariais; também atua como uma grande máquina hierarquizada e centralizada, por meio de estruturas governamentais, com atuação internacional, que propõem uma uniformidade por meio de um conjunto de ações que gerem a produção de competências necessárias ao mundo econômico, como critérios comparativos e ações de boas práticas.

Com a presença dessas forças que alteram sua órbita, a escola obrigatoriamente tornou-se mais flexível e inovadora, para assujeitar-se e acomodar-se à lógica do mercado. Para tanto, conduz-se por uma "pedagogia 'não diretiva' e 'estruturada de modo flexível', [com] o uso de novas tecnologias, [e um] amplo 'cardápio' oferecido aos estudantes" 14 | INTEREDU № 5 VOL. II (DiCIEMBRE 2021) PÁGs. 11-39. ISSN: 2735-6523 
(Laval, 2019, p. 64). Isso posto, os currículos e seus conhecimentos passam a orientar-se pelas necessidades do mercado neoliberal, bem como a produzir subjetividades que se integrem a essa razão de mundo.

É sob o julgo da razão neoliberal que o Governo do Estado de São Paulo vem reformulando suas políticas educacionais, particularmente atuantes sobre a rede pública sobre sua égide, com profundas modificações a partir de 2008, decorrente de resultados avaliativos ruins. Essa reformulação propôs uma reforma qualitativa, com a busca por resultados quantificados em uma certa qualidade. Para tal, reformulou o currículo e ampliou a centralização da gestão educacional mediante normas e metas educacionais. Sob o bojo dessa reforma, em 2012 um novo projeto de reformulação do ensino estadual foi posto em prática, ainda em caráter experimental: o Programa Ensino Integral (PEI), estruturado a partir do projeto Escola da Escolha, desenvolvido pelo Instituto de Corresponsabilidade pela Educação (ICE). Esse projeto incorporou, à rede educacional do estado de São Paulo, o Projeto de Vida, que busca dar protagonismo aos estudantes no desenvolvimento de seus sonhos.

É esse projeto que buscamos apresentar e problematizar neste artigo, e os processos de subjetivação que ele desencadeia nos alunos. Para tanto, inicialmente apresentamos brevemente a origem e a implementação do Programa Ensino Integral na rede pública estadual de São Paulo, para na sequência discutirmos o Projeto de Vida e sua perspectiva de protagonismo no mundo contemporâneo. Continuando, argumentamos e problematizamos a subjetivação desencadeada por essa reforma escolar, e apresentamos nossas considerações finais. 


\section{PROGRAMA DE ENSINO INTEGRAL}

A partir da promulgação da Lei n⿳0 1.164, complementada e alterada pela Lei $\mathrm{n}^{\mathrm{o}}$ 1.191, instaurou-se o Programa Ensino Integral (PEI) como uma nova proposição educacional para o Estado de São Paulo e com a finalidade de aprimorar e alavancar a qualidade da educação oferecida pela rede pública estadual, observando valores de qualidade, de valorização dos educadores, de gestão escolar democrática e cooperativa, de mobilização e comprometimento de toda a sociedade em torno do processo de ensino e aprendizagem, e de uma escola como centro irradiador de inovação.

A implantação desse novo modelo baseou-se na perspectiva de uma formação para os jovens do mundo contemporâneo, os novos cidadãos deste novo século, o XXI; uma educação em acordo com o momento e as necessidades desses alunos, possibilitando aos mesmos sua inserção nas demandas de um mundo em constantes mudanças sociais, culturais entre tantas outras, bem como das relações de trabalho. Para tanto, de acordo com Voorwald e Souza (2014) -responsáveis pela implementação do PEI-, o programa foi concebido, sobretudo, a partir de "duas questões fundamentais: a atenção às demandas decorrentes de pesquisas e avaliações que apontavam o caminho a seguir em busca de uma escola de qualidade; e o resultado de experiências educacionais em aplicação tanto dentro quanto fora do país" (Voorwald y Souza, 2014, p.19).

Por conseguinte, de acordo com os autores supracitados, o objetivo foi aprimorar a qualidade da educação oferecida pela rede pública estadual, bem como proporcionar aos jovens alunos a oportunidade de constituírem projetos de vida sob a mediação escolar, e a partir da composição de um conjunto de metas para que estes projetos possam se 
alicerçar e desenvolver, possibilitando uma melhor inserção e absorção desses jovens no e pelo mundo, e para além das relações escolares. Voorwald e Souza (2014, p.19), indicam uma escola que "obrigatoriamente, que [levasse] adiante um programa que oferecesse aos alunos que nele ingressassem a possibilidade de se dedicarem a um verdadeiro Projeto de Vida".

Antes de explorarmos esse Projeto de Vida, questão de nosso interesse neste artigo, destacamos outra particularidade do projeto, esse em consonância com as propostas articuladas de renovação da educação pública paulista iniciada em 2008: o aprimoramento da qualidade de educação oferecida.

No intuito de aprimorar a qualidade do ensino ofertado pela rede pública estadual, a Secretaria de Educação do Estado de São Paulo [SEE] contemplou experiências educacionais consideradas exitosas no Brasil e em outros países, que atendessem um modelo de qualidade para o desenvolvimento do jovem do século XXI, e estivessem coadunados com os quatro pilares da Educação adotados pela Organização das Nações Unidas para Educação, a Ciência e a Cultura (UNESCO): o aprender a conhecer, aprender a fazer, aprender a viver juntos e aprender a ser ${ }^{1}$.

Por conseguinte, o modelo constituído pelo Ginásio Pernambucano, centrado em um projeto de vida dos alunos, mostrou-se o modelo mais adequado para a implantação no Estado de São Paulo de escolas de ensino integral. Fundamentado "em princípios educativos e premissas que orientam as ações da escola com vistas ao desenvolvimento integral do educando" (Secretária de Educação [SEE], 2015, p.14), tornou-se a referência para a implantação do PEI na rede pública de ensino do Estado de São Paulo.

1 Delors, J. (2003). Educação: um tesouro a descobrir. (2a ed., pp.89-102). Cortez/MEC-UNESCO. INTEREDU № 5 Vol. II (DiciEMBre 2021) PÁGs. 11-39. ISSN: 2735-6523| 17 
A experiência de ensino integral desenvolvida pelo Ginásio de Pernambuco tem seu início em 2003, a partir da proposta do ICE, originado do Programa de Desenvolvimento dos Centros de Ensino Experimental (PROCENTO), programa de educação com o intuito de promover uma "uma nova forma de ver, sentir e cuidar da juventude, contribuindo para a formação de jovens autônomos, solidários e competentes" (Magalhães, 2008, p. 10), decorrente da parceria de um grupo de empresários e a Secretaria de Educação de Pernambuco, em 2002.

O ICE buscou conceber um novo modelo de escolas, baseado no tempo integral e com foco inicial no ensino médio, com posterior expansão para o ensino fundamental. Essa parceria entre o ICE e a Secretaria de Educação de Pernambuco no desenvolvimento e ampliação dos PROCENTROS, possibilitou a emergência, em 2004, da primeira Escola da Escolha, no então Ginásio de Pernambuco, que fora anteriormente reformado pelo grupo de empresários criadores do ICE. "O Ginásio Pernambucano foi o ponto de partida da Causa da Juventude com a concepção de um Modelo de educação inovador denominado Escola da Escolha e cujo foco é o Jovem e a construção do seu Projeto de Vida" (Instituto de Corresponsabilidade pela Educação [ICE], 2021a, parágrafo 3).

A Escola da Escolha é o modelo de educação integral criado pelo ICE. Ele se contrapõe a outros modelos de educação integral ${ }^{2}$ vigentes no Brasil, o que lhe permite se apresentar "como uma nova escola para a juventude brasileira" (ICE, 2021b, parágrafo 1). A Escola da Escolha pressupõe um modelo escolar de excelência que amplie as referências dos

\footnotetext{
2 Não é objetivo deste texto discorrer sobre os modelos de ensino integral vigentes no Brasil desde a Constituição de 1988 e a Lei de Diretrizes e Bases de 1996, nem sobre a história do ensino integral. Mas demarcar a entrada de uma proposta diferente das presentes na educação pública do Estado de São Paulo a partir de 2012.
}

18 | INTEREDU № 5 VOL. II (DicIEMBRE 2021) PÁGS. 11-39. ISSN: 2735-6523 
valores e ideais dos estudantes, a fim de que estes possam enfrentar os desafios do século XXI. Para tanto, organiza-se a partir da Base Nacional Comum Curricular (BNCC) e de uma formação diversificada para a constituição de um currículo que atenda as demandas oficiais e as demandas dos próprios alunos e da sociedade.

Esse currículo, em consonância com as orientações da UNESCO, orienta-se pelo desenvolvimento de habilidades e competências pessoais, sociais e cognitivas, uma "combinação entre conhecimento e atitude [...] decisiva no sucesso do estudante, nas distintas dimensões de sua vida, seja pessoal, social ou produtiva" (ICE, 2021b, parágrafo 6). O desenvolvimento desse currículo sustenta-se na ampliação da permanência do aluno e da equipe escolar na escola, por meio das normas já dispostas no arcabouço jurídico-educacional brasileiro, possibilitando a emergência do "Projeto de Vida", em que a escola se torna o lugar ideal para apresentar

as condições fundamentais para a formação do estudante como uma pessoa autônoma, portanto, capaz de tomar decisões baseada nos seus conhecimentos e valores; solidária, envolvendo-se como parte da solução de problemas e competente porque reconhece que o que aprendeu a durante a educação básica, não deve ser suficiente para a execução do seu Projeto de Vida e assim, ele deve continuar aprendendo ao longo da sua vida (ICE, 2021b, parágrafo 6).

Desse modo, o estudante e seu Projeto de Vida direcionam o desenvolvimento pedagógico da Escola da Escolha. São os sonhos, as ambições, os desejos do estudante que fazem pulsar a educação escolar, tornando a própria educação parte de sua vida, visto que somente por ela poderá almejar e ser quem pretende nas mais diferentes esferas do mundo social e do trabalho. A proposta da Escola da Escolha empurra o 
protagonismo educacional para o aluno, alterando a órbita educacional, visto que o corpo escolar se torna apoio para o protagonismo dos alunos por meio do Projetos de Vida.

Foi esse modelo educacional que, depois de ampliado pela rede pública do Estado de Pernambuco, tornou-se referência para a rede pública estadual de São Paulo, implementado, em caráter experimental, em 16 unidades escolares no ano de 2012.

PROJETO DE VIDA E PROTAGONISMO NO PROGRAMA DE ENSINO INTEGRAL

Antes de aprofundarmos na discussão do Projeto de Vida e no protagonismo dos alunos, temos como importante reafirmar que esse é o ponto novo, a novidade de um novo modelo de escola de tempo integral, indicando que estse projeto é a continuidade da reforma educacional e curricular iniciada em 2008 no Estado de São Paulo, com o projeto "São Paulo faz Escola", quando já estavam postas as relações de qualidade, os desafios do momento contemporâneo, o alinhamento com a proposta educacional da UNESCO, bem como a presença de escolas de tempo integral, que já eram parte da rede de ensino desde 2006.

A reforma de 2008 apresentou-se com o questionamento da autonomia proporcionada às escolas pela LDB (1996), propondo a centralização das decisões por meio de uma "nova" proposta curricular, com a finalidade de as escolas funcionarem como uma rede integrada, a fim de promover conhecimentos e competências comuns a todos os alunos. Para tanto, já indicava os desafios presentes no século XXI e a necessidade de adequar a escola a esses desafios ainda não contemplados pela formação oferecida; logo, ofertava soluções que tornavam as escolas 
capazes de enfrentar esses desafios e de prepararem os alunos para esse novo momento e as pressões decorrentes.

Esta reforma também teve foco na qualidade, visto que somente por uma educação que priorizasse a qualidade, os alunos das escolas públicas estaduais poderiam ter "uma bela oportunidade de inserção produtiva e solidária no mundo" (Secretaria de Educação [SEE], 2010, p. 9), com essa tal "qualidade" de educação proporcionando aos alunos a inclusão ou exclusão de grupos sociais, bem como tornando-os críticos e capazes de agir com autonomia, inserindo-os nas dimensões sociais e produtivas cidadãs.

Como estão a escola preparando-se para assumir plenamente sua cidadania, todos devem passar pela alfabetização científica, humanista, linguística, artística e técnica para que sua cidadania, além de um direito, tenha qualidade. $\mathrm{O}$ aluno precisa constituir as competências para reconhecer, identificar e ter visão crítica daquilo que é próprio de uma área de conhecimento e, a partir desse conhecimento, avaliar a importância dessa área ou disciplina em sua vida e seu trabalho (SEE, 2010, p. 20).

Portanto, a escola e o aluno preconizado pela reforma de 2008 é alguém à altura dos desafios contemporâneos para as transformações tecnológicas, históricas, culturais que o credenciem para a prática cidadã; é também um aluno preparado com qualidade para os desafios que o contemporâneo apresenta. Para alcançar essa pretendida qualidade, segundo Maria Helena G. Castro, propõe-se uma escola que também aprenda, o que, aos olhos da SEE, traduz-se por uma escola em constante busca por novos modos de tornar interessante e atraente a educação ali proposta, através de "uma abordagem mais inspiradora e dinâmica, adequada ao público jovem a que se destina" (Fini, 2008, p. 3). 
Complementando o ensejo de qualidade e os desejos de juventude escolar, o ponto central do PEI é dar suporte ao Projeto de Vida, incentivando os jovens a construírem um objetivo para suas vidas e garantir que não sejam abandonados -os jovens e os sonhos- durante o caminho escolar. Como ponto central, a referência para a convergência das ações educativas, sem perder a excelência acadêmica, a formação para o mundo do trabalho e de valores. Para tanto, a atividade que, inicialmente, promove tal suporte, recebe o sugestivo nome de "Acolhimento", pois visa a recepção dos novos alunos por alunos "acolhidos" em anos anteriores, apresentando "as primeiras orientações acerca dos fundamentos e princípios do Ensino Integral e, por meio de dinâmicas de grupo são levados a refletir o que esperam da vida" (SEE, 2015, p. 19).

Por conseguinte, a convergência para o Projeto de Vida, ocorre nos primeiros dias de aula com o acolhimento pelos alunos, anteriormente "acolhidos", e pela orientação para pensarem quem são e quem querem ser no futuro, traçando metas que possibilitem alcançar seus objetivos. Incentiva-se também a refletirem sobre perseverança, obstáculos, valores etc. Essa apresentação vem acompanhada da elaboração pelos alunos de dois documentos que esboçam seus planos: "Quem sou eu" e "Escalada dos Sonhos" (para o ensino fundamental recebe o nome de Escada dos Sonhos). No primeiro, os alunos refletem sobre suas memórias, sua herança social, e quais caminhos devem construir a partir de história sociocultural e econômica. No outro, articulam metas temporais para seus projetos de vida vinculadas à inserção no mercado de trabalho.

São esses documentos que orientaram a equipe escolar na elaboração de um plano curricular que englobe as premissas dos alunos, bem como das escolas, vinculadas a planos de ação preparados pela SEE 22 | INTEREDU № 5 VOL. II (DiCIEMBRE 2021) PÁGs. 11-39. ISSN: 2735-6523 
com metas a serem alcançadas. Ou seja, apesar de o ponto central ser o aluno e seu Projeto de Vida, há uma forte vinculação das unidades escolares a planos direcionados pela SEE, indicando a continuidade do plano de 2008, de centralidade decisória e com o objetivo de estabelecer uma qualidade de ensino e respeito à certas normas curriculares. Cabe a escola acrescentar outros planos que não conflitam com as normas da SEE e auxiliem os alunos em seus Projetos de Vida.

Essa limitação fortalece um certo protagonismo oriundo dos alunos, mas também evidencia que há regras muito claras para esse protagonismo, visto que escola e professores atuam mais como força organizacional entre a SEE e o "desejo" dos alunos, a fim de que esses dois campos possam estabelecer um diálogo profícuo, possibilitando que tanto as normas e metas estipuladas pela SEE sejam cumpridas pela escola, promovendo a qualidade esperada, quanto o Projeto de Vida dos alunos tenha a possibilidade de realizar-se.

Para tanto, cabe à escola desenvolver uma parte diversificada, visto que o PEI funciona com um horário ampliado, que não interfira na aplicação obrigatória do currículo oficial e da BNCC. Esse é o momento que permite a professores e gestão escolar produzirem inovações ao modelo estabelecido pela SEE, com foco no Projeto de Vida dos alunos, organizando e reordenando tempo, espaço e disciplinas, de modo a colaborarem com o desenvolvimento dos projetos propostos pelos alunos.

Esse modelo enfatiza a importância do protagonismo para uma formação cidadã, segundo as Diretrizes do PEI (Secretária de Educação [SEE], 2012), possibilitando aos alunos a capacidade de se organizarem e organizar os espaços em que estão inseridos. Para tanto, estimula-se a formação de lideranças que atuarão no acolhimento dos novos alunos, como líderes de turma (cada classe tem o seu líder) e na produção de atividades paralelas ao currículo e à BNCC, como os Clubes Juvenis, 
organizados pelos próprios alunos, onde o líder de Clube que deve ter habilidades fundamentais de gestão, cogestão e heterogestão -de si próprio-, do conhecimento e do seu projeto de vida.

Estsa proposta de protagonismo opera na formação do aluno para que se torne ao mesmo tempo sujeito e objeto de suas ações, a fim de que atue na resolução de problemas e assumaassuma para si as responsabilidades de decidir não somente sobre atividades que quer desenvolver no âmbito escolar, mas também nas dimensões de toda uma vida por meio de seus sonhos e ambições; logo, a responsabilidade por suas escolhas na vida. Por conseguinte, a produção de uma juventude autônoma e solidária, no sentido de se ver como parte da solução, por ser capaz de avaliar a situação e propor respostas e decisões a partir de seus interesses intermediados por sua subjetividade, tornando-se "competente para compreender gradualmente as exigências do novo mundo do trabalho e preparado para a aquisição de habilidades específicas requeridas para o desenvolvimento do seu Projeto de Vida" (SEE, 2012, p. 15).

O exercício desste protagonismo, a partir do Projeto de Vida, alicerça-se sobre um dos pilares do projeto da UNESCO, o "aprender a aprender"; ou seja, uma escola que aprende (Secretaria de Educação [SEE], 2008), projeta alunos que aprendem a aprender, por meio de "uma metodologia inovadora, que articula o desenvolvimento tecnológico, a diversidade de modelos dinamizadores da aprendizagem e as mídias interativas [...] para atender às demandas de uma sociedade cada vez mais exigente e competitiva" (Kuenzer, 2017, p. 337). Esse modelo de protagonismo, de projetos de vida por meio de escola flexível traduz-se pela passagem de um aluno, até então, espectador para um aluno responsável pela sua própria aprendizagem, que estimula a presença e a 
produção de competências, como iniciativa, autonomia, disciplina, comprometimento, responsabilidade social.

Kuenzer (2017) também enfatiza que esse modelo tem finalidade a formação de profissionais flexíveis, posto que a política educacional se sustenta sobre a máxima do aprender a aprender; logo, um modelo que exprime as mudanças tecnológicas postas diante do mundo do trabalho, de uma aprendizagem dinâmica e flexível que se complementa ao longo de sua vida profissional, em que o protagonismo permite "em tese, ao gerenciar seus tempos e espaços, aprenderia a aprender, sozinho ou em colaboração, o que conduziria a um melhor aproveitamento" (Kuenzer, 2017, p. 338).

\section{ATRAVESSAMENTOS NEOLIBERIAS NA SUBJETIVIDADE ESCOLAR}

Agamben, no ensaio $O$ rosto (2017, p. 87-88), argumenta que a emergência de um rosto está demarcada na linguagem que "não tem, por isso, nenhum conteúdo real, não diz a verdade sobre esse ou aquele estado de espírito ou de fato, sobre este ou aquele aspecto do homem ou do mundo: é apenas abertura, unicamente comunicabilidade". Entretanto, a emergência de um rosto, segundo o autor, distingui algo ou alguém dos demais ao receber um nome, um nome próprio e particular, constituindo um campo de batalha, pois esta exposição produz abalos no campo político, pela manifestação de uma verdade, de sua própria verdade.

Desse modo, a presença do rosto no campo político não está no campo do simulacro, sob a ordem da ocultação de uma verdade, mas do simultâneo, da multiplicidade de rostos que ocupam e disputam o mesmo espaço, o que não permite que um seja mais verdadeiro que outro. "Colher a verdade do rosto significa apreender não a semelhança, mas a simultaneidade das faces, a potência inquieta que as mantém juntas e que as reúne" (Agamben, 2017, pp. 93-94). 
Com a emergência do discurso de uma nova escola, de uma escola voltada para os desafios do contemporâneo, de certa qualidade almejada, revela-se o rosto de um outro sujeito para o campo escolar, um jovem que toma para si o protagonismo de suas ações, protagonismo que está exposto no Projeto de Vida proposto pela reforma educacional PEI, pelo Estado de São Paulo. A emergência de um rosto exposto, político, que toma e torna o mundo um campo de batalha, de guerra; um espaço político espelhando o verdadeiro, as verdades próprias a cada rosto. Por conseguinte, o protagonismo espelhado pelo Projeto de Vida, são fragmentos dessa guerra presente no contemporâneo entre projetos educacionais que se contrapõem e que projetam a formação de uma verdade, bem como de um modelo de sujeito.

Foucault (2011a) nos alerta que a verdade, assim como o conhecimento, é produto da ação humana, a partir de múltiplas coerções que organizam o espaço, via discursos e instituições, como as de ensino, que produzem o conhecimento, difundem e o tornam objeto de consumo, e, de tal feita, objeto de disputa, que tem a sua emergência no apaziguamento de contradições decorrente do embate entre forças. Desse embate, no contemporâneo emerge aquilo de Dardot e Laval (2016) denominam de "nova razão do mundo", um sistema normativo, uma racionalidade governamental que movimenta, acelera e exacerba aspectos da Modernidade ${ }^{3}$ oitocentista e seus ideais; tempos hipermodernos, de um governo dos homens com estratégia global, integrando o mundo e todas as dimensões da existência humana.

Para Dardot e Laval (2016) o neoliberalismo alterou e reformulou radicalmente o exercício de governamentalidade, atuando sobre

3 Modernidade compreendida como episteme, como discute Michel Foucault em As palavras e as coisas: uma arqueologia das ciências humanas.

26 | INTEREDU № 5 VOL. II (Diciembre 2021) PÁGS. 11-39. ISSN: 2735-6523 
motivações sociais e subjetivas, produzindo formas de existência e modos de viver, modificando como nos relacionamos conosco e com os outros: produto de um regime de verdades e subjetivações específicas que regem um modo de viver e de existir. No neoliberalismo, um conjunto de condutas e comportamentos que ordenam a organizam uma sociedade caracterizada pela competição generalizada e pelo empresariamento de si: um modelamento baseado no mercado.

Para Foucault (2010), essa razão neoliberal manifesta-se como um outro e novo modo de objetivar e subjetivar os indivíduos pela aspiração de total liberdade em todos os campos da vida humana. Com seu fortalecimento, tornou-se um sistema normativo, que por meio de técnicas de poder diferentes às usuais, e com influência sob todo o planeta, reformou a racionalidade de governo, por conseguinte, as relações sociais e as esferas da existência.

Assim, a razão neoliberal movimentou os discursos para o campo das reformas, como o do dispositivo escolar, seja pela inovação pedagógica ou pela incorporação de novos dispositivos tecnológicos ou midiáticos, a fim de promover profundas mudanças de ordem sobre uma sociedade antes organizada a partir do coletivo para o individual. Por conseguinte, toma a educação como um bem mais econômico do que social, político e cultural, apostando, primordialmente, no empreendedorismo, bem como na competitividade e na rentabilidade do capital humano.

E esse caráter do neoliberalismo atravessa o modelo proposto para a Educação no Estado de São Paulo, que, por meio de um conjunto de reformas, busca por uma integração centralizada, pela instituição rotineira de algo novo, de novidades à proposta curricular, com a finalidade e o desejo de promover conhecimentos e competências comuns a todos os alunos, e auferidos através de processos avaliativos. É esse 
conjunto de alterações legislativas e protocolares, que priorizaram, a partir da reforma iniciada em 2008, melhores resultados e qualidade, que continuamente sofre correções, reordenando sua rota e enfatizando inovações que buscam solidificar um intervencionismo estatal na produção de saberes que priorizem o estabelecimento de regimes de verdade, que denominamos como um modo de vida neoliberal.

Contraditoriamente a certo discurso neoliberal que cobra menor participação do Estado sobre o mercado e a sociedade, Foucault (2010), Lazzarato (2013, 2017), e Dardot e Laval (2016) reafirmam que a ação neoliberal é exatamente o oposto: é uma política de intervenção de um Estado-estrategista, de apoio, de defesa do mercado amparada na globalização que acelerou os processos de concorrências local e mundial, e, desse modo, objetiva, por meio de leis antinaturais, a concorrência entre indivíduos, como norma de conduta e o modelo empresarial, como modo de subjetivação, para o enfraquecimento das políticas de bem-estar social.

O pensamento dos autores supracitados esclarece e localiza o discurso reformista da rede pública estadual de ensino de São Paulo, que tem, como sua primeira premissa, exatamente na centralização das políticas curriculares e na implantação de novos modelos de gestão, o esvaziamento da independência e da pluralidade que a LDB permitia às escolas, pois somente com um conjunto de políticas equilibradas pelo binômio Mercado-Estado, certa qualidade pode ser auferida a partir de testes e metas.

Para Dardot e Laval (2016) o neoliberalismo atua sobre o espírito da democracia, não a extinguindo, mas a esvaziando, aumentando o controle sobre a sociedade pela ação dos governantes, e, de maneira oposta, impedindo a ação do Estado sobre o direito privado. Já Lazzarato (2013, 2017) observa que ao dimensionar cálculos futuros, antecipando condutas 28 | INTEREDU № 5 Vol. II (DiCIEMBRe 2021) PÁGs. 11-39. ISSN: 2735-6523 
comportamentais, o neoliberalismo interfere sobre a relação temporal presente e futuro, aproximando-os; e ao totalizar ações, condutas, comportamentos, dificulta ações políticas locais, enfraquecendo a possibilidade de escolhas e alternância presentes no processo democrático.

Desse modo, é sobre esse terreno centralizado que o Estado de São Paulo funda pilares, a cada nova "renovação" ou "novidade" educacional, apresentando um modelo que se apresenta como democrático, mas age sobre o seu esvaziamento, como escrevem por Dardot e Laval (2016), pois atua a partir da centralização da rede e com metas e normas pré-estabelecidas, permitindo um espaço menor de protagonismo dos demais corpos escolares, particularmente dos estudantes, como no Projeto de Vida, apesar de aparentemente se "vender" como ampliação das liberdades individuais.

Para Foucault (2011b) a escola, como força produtiva atua sobre os modos de viver, na constituição de verdades, por jogos de poder, como uma "instituição de sequestro" por meio de práticas, técnicas e tecnologias a serviço da produção de um saber específico, inventando modos de ser, agir, compreender e interpretar o mundo; normalizando sentidos, emoções e desejos; Essa força produtiva a coloca como um objeto de desejo, um ativo para o fortalecimento de captura de corpos, na difusão de saberes e criação de sujeitos que o mundo necessita para existir. Essa existência é reafirmada aos estudantes pelo Projeto de Vida, ao escrever, e inscrever, sobre estes corpos modos de existir capacitados a atuarem sobre um modelo específico de existência, aqui o que a lógica neoliberal confere ao mundo.

Assim, esse projeto, ao propor que os alunos desenvolvam seus sonhos, imprime sobre eles os sonhos do mundo contemporâneo, propõe um sonhar diagramado pelas necessidades de corpos que a razão neoliberal normatiza. Como um duplo-dispositivo, que tem "de algum 
modo a capacidade de capturar, orientar, determinar, interceptar, modelar, controlar e assegurar os gestos, as condutas, as opiniões e os discursos dos seres viventes" (Dardot y Laval, 2016, p. 40), o Projeto de Vida dispara processos de subjetivação constituídos por uma norma (Foucault, 2011b), que, a partir de todo e qualquer governamento, atua sorrateiramente sobre nós, normalizando e naturalizando o mundo.

Gallo (2013) argumenta, a partir de Vigiar e Punir, obra de Michel Foucault, que a escola além de proporcionar o sonho iluminista de produção de uma maioridade, também atua na produção disciplinar, como uma tecnologia de poder que produz corpos dóceis, produzindo certo tipo de assujeitamento, de sujeitos formatados para um modelo de sociedade. O neoliberalismo, como modelador da sociedade, apropria-se da máquina pedagógica para formar corpos produtíveis e úteis a suas aspirações de governamento.

É sob esta condição que os projetos que propõem inovar o sistema educacional público do Estado de São Paulo, buscam ampliar a reforma iniciada em 2008, como o programa Educação -Compromisso de São Paulo-, iniciado em 2011, que se baseia em uma "fictícia" mobilização da sociedade, pois estruturado e organizado de modo centralizado e hierárquico, propõe o engajamento e um pacto entre sociedade e governo para uma educação de qualidade. Este programa, foi estruturado em 5 pilares para nortear a atuação e a criação de novos projetos da SEE.

Os 5 pilares para a reforma educacional de rede pública do Estado de São Paulo, com foco na qualidade da educação pública, propõem a valorização do capital humano (1ำ pilar), ou seja, a valorização do profissional da educação; a melhora da gestão pedagógica, com novos programas focados na qualidade de ensino ( $2^{\circ}$ pilar); a implantação de um novo modelo de educação integral, que posteriormente originou as 30 | INTEREDU № 5 VOL. II (DiCIEMBRE 2021) PÁGs. 11-39. ISSN: 2735-6523 
PEI (3º pilar), o aprimoramento da gestão organizacional e financeira, com foco no fomento e investimentos da Educação ( $4^{\circ}$ pilar); e a mobilização e engajamento da sociedade para alcançar uma escola de qualidade (5 pilar) (Secretária de Educação, s.f.).

Estes pilares produzem disciplinamento, os corpos dóceis do contemporâneo, sob a condução da razão neoliberal, ostentando o nome de empreendedor de si, um homem-empresa que oferece como produto seu capital humano ( $1^{\circ}$ pilar), aquilo que o constitui, seu corpo biológico, e o que acumulou; ou seja, como capital oferece um conjunto de fatores físicos e psíquicos, aptidões e competências. Por conseguinte, não é mais meramente uma força física que alimenta e movimenta a máquina, mas uma máquina que pelo jogo do mercado produz rendimentos-salário: o capital-investimento de uma empresa; bem como derivações de investimentos voluntários, externos e ambientais do desenvolvimento individual: aquilo que aprendeu e a forma como viveu sua vida, em suma, aquilo que o corpo é capacitado a oferecer física, psíquica e intelectualmente. $\mathrm{O}$ sujeito torna-se seu próprio capital; a empresa, o produtor de um produto que é ele mesmo, que se vende como produto, um parceiro dentro de um sistema de trocas, transfigurado, no neoliberalismo em empresário de si mesmo.

O exercício do protagonismo do aluno proposto pelo Projeto de Vida, reverbera os sons do contemporâneo, a condução por uma razão neoliberal; logo, esste projeto busca normatizar as condutas dos estudantes, produzindo-as por um conjunto de técnicas e práticas que os incorporam aos aparelhos de produção como força produtiva, implicando em resultados profundos e duradouros de relações de que não se escapam.

Nessas forças localizam-se a formação de um capital humano que demanda um conjunto de elementos, investimentos individuais e coletivo-governamentais para sua produção. Formatados como sujeitos 
econômicos, empresários de si mesmo, convertemo-nos em empresa, assumimos e nos responsabilizamos pelos custos, recursos, investimentos e riscos que todas as empresas estão sujeitas. A esta relação, Lazzarato $(2013,2017)$ argumenta que sob o neoliberalismo os conceitos de empreendedor de si mesmo e de capital humano devem ser incorporados e interpretados a partir da relação credor-devedor, para melhor compreender o modo neoliberal de governar.

Reafirmamos a proposta de protagonismo presente no Projeto de Vida, em que o aluno assume a responsabilidade de escolher atividade, mas também de domar o domínio de todas as suas escolhas pela vida, assumindo total responsabilidade por elas. É importante frisar que o Estado, via escola pública é fiador desta proposta, e o corpo escolar tem a função de mediar e possibilitar que estes projetos possam ser desenvolvidos pelos alunos, desde que não interfiram em normas e metas pré-estabelecidas.

Metaforicamente, afirmamos que ao aluno é creditado a possibilidade de metamorfosear seus sonhos, seus desejos em realidade, a partir do Projeto de Vida. Entretanto, o Estado, como fiador da proposta educacional, e o corpo escolar, como mediador das práticas de ensino, atuam apenas como agências fomentadoras, e não se responsabilizam pelo crédito tomado compulsoriamente pelo aluno. Nessa relação do crédito, sempre haverá devedor. No neoliberalismo a relação credordevedor inclui a todos, de tal modo que a figura do "homem endividado" seja, escreve Lazzarato (2013, 2017), a pedra angular para a governamentalidade neoliberal, acompanhando o homem durante toda sua vida, desde o nascimento até a sua morte

Em outras palavras, argumentamos que ao propor que os alunos, via política educacional, assumam o protagonismo de suas vidas e se 32 | INTEREDU № 5 VOL. II (DiCIEMBRE 2021) PÁGs. 11-39. ISSN: 2735-6523 
tornem responsáveis pelo desenvolvimento de seus projetos e sonhos, que se responsabilizem pela trajetória escolhida, Estado e escola atuam e produzem subjetivamente sujeitos que, mergulhados em uma razão neoliberal, devem atuar como empresas, devem constituir-se como empreendedores de si, pois este é o mundo e os desafios do contemporâneo que a proposta de uma nova escola apresenta e representa.

Sob a razão neoliberal, o homem-empresa, o empreendedor de si, o protagonista de si, endividado ocupa o espectro que vai do cidadão ao consumidor, modelo e paradigma de uma ética e de exercício político. Porquanto estar endividado não é um exercício de força ou repressão do credor para com o devedor, mas um exercício de liberdade, livre para projetar sua vida para poder honrar, estar em dia com passivos e compromissos contraídos. Consequentemente, a consciência de uma culpabilidade pelo fracasso, pelo erro, como produtor/produto e como consumidor.

Ao estudante que assume o protagonismo de sua vida, o exercício da liberdade por escolher o melhor caminho para o desenvolvimento de sua formação, atua em paralelo um processo de subjetivação, uma dívida para consigo mesmo pelos compromissos assumidos e não honrados, para consigo, para com a escola, com os amigos, com a comunidade, com a sociedade, com o Estado. Nessa tênue linha entre passivos e ativos, o aluno empreendedor de si encontra-se naquilo que Han (2017) denomina de "sociedade de desempenho", em que a maximização da produção e a valorização de conceitos de projeto, iniciativa e motivação, produz depressivos e fracassados, em decorrências da necessidade de iniciativa e responsabilização individual.

Dardot e Laval (2016) apontam que a razão neoliberal estimula a competição e a flexibilização, com o propósito de produzir sujeitos que sejam mais eficazes, inovadores e adaptativos ao mundo, para que 
possam sobreviver ao combate contínuo a que estão expostos, sob os auspícios de "ajuda-te a ti mesmo".

Trata-se do indivíduo competente e competitivo, que procura maximizar seu capital humano em todos os campos, que não procura apenas projetar-se no futuro e calcular ganhos e custos como o velho homem econômico, mas que procura sobretudo trabalhar a si mesmo com o intuito de transformar-se continuamente, aprimorar-se tornar-se sempre mais eficaz. O distingue esse sujeito é o próprio processo de aprimoramento que ele realiza sobre si mesmo, levando-o a melhorar incessantemente seus resultados e desempenhos. Os novos paradigmas englobam tanto o mercado de trabalho como o da educação e da formação, 'formação para toda vida' (long life trainig) e 'empregabilidade', são modalidades estratégicas significativas (DARDOT, LAVAL, 2016, p. 333).

Enredados pelas teias da razão neoliberal, os alunos envolvidos pelas tramas do Programa Ensino Integral e do Projeto de Vida se vêm obrigados compulsoriamente a anteciparem e projetarem seu futuro sob um presente incerto, que são as relações disparadas pelas crises que alimentam o neoliberalismo. Ao tomar posse do discurso escolar, o paradigma neoliberal produz os sujeitos que lhe são necessários para a sua própria existência, e, por conseguinte, catapulta experiências de vida que hão de se conformar a práticas, disputas e modos de existência antes restritas ao campo corporativo, em que a liberdade de inventar e criar mundos caminha paralelamente ao diagnóstico e as consequências do fracasso e do esquecimento. Os sujeitos dessa nova escola, dessas reformulações educacionais, são sujeitos que serão soltos em mundo que 
ao mesmo tempo requirirá adaptabilidade e invenção, responsabilidade e competição; protagonismo individual e empresarial.

\section{CONSIDERAÇÕES FINAIS}

A partir da constituição de uma nova agenda educacional, por meio do projeto São Paulo faz Escola (SEE, 2008), foram introduzidos conceitos de competências e habilidades na rede estadual de São Paulo, como processos para confrontar os desafios que a escola e os alunos encontram na sociedade contemporânea, favorecendo às relações do trabalho e da vida cotidiana. Essas premissas estão no cerne de todas as mudanças que ocorridas desde então.

A partir de 2012, com a implementação de uma nova perspectiva para o ensino de tempo integral com a implementação do Programa Ensino Integral, e a emergência de uma política educacional que priorizou o protagonismo dos alunos por meio do Projeto de Vida, ampliou-se os processos de subjetivação que atuam sobre os alunos, a partir de uma pedagogia que consiste em aprender a aprender, que objetiva a processos de "competência de organização, comunicação, adaptabilidade, trabalho em equipe, resolução de problemas em contextos da incerteza" (Laval, 2019, p. 64), decorrendo, desta incerteza, entraves existenciais e profissionais permanentes que exigem forte flexibilização.

Foi esse processo de subjetivação que buscamos explorar, a fim de problematizar a constituição desses sujeitos atravessados por uma política educacional tensionada pelas incertezas próprias da vida e de um mundo conduzido pela razão neoliberal, que parece ter na crise das instituições seu alimento. Fruto dessas crises é o sujeito que é constituído no e pelo neoliberalismo, e incerto é o mundo que o cerca.

Nesse jogo de subjetivação, não poderia escapar ao processo educacional o modelo que emergiu a partir da razão neoliberal, de um INTEREDU № 5 Vol. II (DiCIEMBRE 2021) PÁgs. 11-39. ISSN: 2735-6523| 35 
sujeito moldado pelo jogo corporativo, que se transforma em um empreendedor de si e que transporta o futuro para o presente, pois, sob as regras do mercado, a concorrência o obriga a flexibilizar-se e inventarse a todo momento, sempre aprendendo. Essas exigências transformam o mundo num lugar sem descanso e sem mistérios, onde só é admitido o que é útil, acessível e se mostra disponível, um modelo temporal que Crary (2014) denomina de 24/7 (24 horas por dia, 7 dias por semana), uma infraestrutura global para o trabalho e o consumo contínuo.

Por conseguinte, uma liberdade ampliada em relação ao corpo social, dos tempos da coletividade, mas também de relações de trabalho anteriores, projetando um corpo que trabalha sem pausa, sem limites, em um mundo que funciona ininterruptamente, e, que não mais preso à limites de tempo e espaço, produtor e produto, objeto de consumo e consumidor, faz o aluno protagonista de seus sonhos, de seu projeto de vida.

Han (2017) afirma que esse sujeito, senhor e soberano de si mesmo, dono de seu tempo, constrói estratégias, planos de ação, estabelece metas que lhe garantam o domínio sobre a própria vida, para que possa conduzi-la na conformidade de seus desejos e necessidades, de tal modo que se submeta somente a si próprio; condição que implica na proeminência dos opostos liberdade e coerção: "na liberdade coercitiva ou à livre coerção de maximizar o desempenho" (HAN, 2017, pp. 29-30), confundindo-se o explorador do explorado, o agressor da vítima.

Essa experiência paradoxal de liberdade, que subjetivamente é construída pela razão neoliberal, e, como tal, nos governa conduzindo nossas relações, é a razão que atua nos processos de subjetivação presente nas escolas da rede pública estadual de São Paulo, mediante a implantação da extensa reforma educacional iniciada em 2008, e ganha 
aprimoramentos a cada novidade, aproximando-a cada vez mais das exigências mundo contemporâneo.

Mundo onde, de acordo com Crary (2014), o sono ainda é a última fronteira não ultrapassada pela lógica da mercadoria, pois nenhum valor, ainda, pode ser extraído do sono. Lugar e espaço de produção de sonhos que não se tornam objetos de consumo, mas de uma imaginação que produz utopias, que se movimentam na busca de experiências, experienciações da vida, sem a pressa, sem a aceleração, que segundo Han (2021, p.13), “destrói as estruturas próprias de sentido e tempo”, que não permite que os olhos se fechem e as narrativas se encerrem.

\section{REFERÊNCIAS BIBLIOGRÁFICAS}

Agamben, G. (2017). Meios sem fim: notas sobre a política. Autêntica.

Crary, J. (2014). Capitalismo tardio e os fins do sono. Cosac Naify.

Dardot, P. y Laval, C. (2016). A nova razão do mundo. Boitempo.

Fini, M. I. (Ed.). (2008). Proposta curricular do Estado de São Paulo. Secretaria de Educação.

Foucault, M. (2010). Nascimento da biopolítica. Edições 70.

Foucault, M. (2011a). Verdade e poder. En R. Machado (Ed.). Microfísica do poder. (pp. 01-14). Graal.

Foucault, M. (2011b). Vigiar e punir: nascimento da prisão. (39ª ed.). Vozes.

Gallo, S. (29 set. a 02 out. de 2013). Em torno de uma educação menor: variáveis e variações. Reunião Nacional da ANPEd, Universidade Federal de Goiás, Goiânia, Brasil. http://36reuniao.anped.org.br/pdfs_trabalhos_encomendados/gt13 _trabencomendado_silviogallo.pdf.

Han, B.-C. (2017). Sociedade do cansaço. (2a ed.). Vozes.

Han, B.-C. (2021). Favor fechar os olhos: em busca de outro tempo. Vozes. 
Instituto de Corresponsabilidade pela Educação (2021a). A história do Instituto de Corresponsabilidade pela Educação (ICE) nasceu de um "acaso" e da trajetória de retomada do ensino de qualidade em Pernambuco. https://icebrasil.org.br/sobre-o-ice/\#nossa-historia.

Instituto de Corresponsabilidade pela Educação (2021b). Um novo jeito de ver, sentir e cuidar dos estudantes brasileiros. https://icebrasil.org.br/escola-da-escolha/.

Kuenzer, A. Z. (2017). Trabalho e escola: a flexibilização do ensino médio no contexto do regime de acumulação flexível. Educação \& Sociedade, 38(139), 331-354.

Laval, C. (2019). A escola não é uma empresa: o neo-liberalismo em ataque ao ensino público. Boitempo.

Lazzarato, M. (2013). La fabbrica del hombre endeudado: ensayo sobre la condición neoliberal. Amorrurto.

Lazzarato, M. (2017). O governo do homem endividado. n-1.

Lei 9.394, de 20 de dezembro de 1996. Estabelece as diretrizes e bases da educação nacional [LDB]. http://www.planalto.gov.br/ccivil_03/leis/L9394.htm.

Lei Complementar n⿳ำ 1.164, de 4 de janeiro de 2012. Institui o Regime de Dedicação Plena Integral (RDPI) e a Gratificação de Dedicação Plena Integral (GDPI). http://www.al.sp.gov.br/norma/?id=165008. Lei Complementar $\mathrm{n}^{-}$1.191, de 28 de dezembro de 2012. Dispõe sobre o Programa Ensino Integral em escolas públicas estaduais e altera a Lei Complementar no 1.164 , de 2012. http://www.al.sp.gov.br/norma/?id=169046.

Magalhães, M. (2008). A juventude brasileira ganha uma nova escola de ensino médio: Pernambuco cria, experimenta e aprova. Albatroz/Loqui. 
Secretaria de Educação (s.f). Iniciativa propõe pacto com a sociedade para tornar a educação paulista uma das melhores do mundo. Compromisso de São Paulo. https://www.educacao.sp.gov.br/compromisso-sp.

Secretária de Educação (2008). São Paulo faz escola. http://www.escoladeformacao.sp.gov.br/portais/Default.aspx?tabi $\mathrm{d}=1022$.

Secretaria de Educação (2010). Currículo do Estado de São Paulo: linguagens, códigos e suas tecnologias. SEE.

Secretaria de Educação (2012). Diretrizes do programa ensino integral. SEE. http://www.educacao.sp.gov.br/a2sitebox/arquivos/documentos/7 26.pdf.

Secretaria de Educação (2015). Caderno do gestor: diretrizes do programa ensino integral. SEE.

Voorward, H. J. C. y Souza, V. (2014). Políticas públicas e educação: o novo modelo de escola de tempo integral. SEE. 